\title{
Resenha \\ Educação Estatística: teoria e prática em ambientes de modelagem matemática
}

Edson Pereira Barbosa ${ }^{1}$

CAMPOS, Celso. R. WODERWOTZKI, Ma. Lúcia. L. e JACOBINI, Otávio. J. Belo Horizonte: Autêntica Editora, 2011.

O livro Educação Estatística: teoria e prática em ambientes de modelagem matemática é resultado de trabalhos do Grupo de Pesquisa em Educação Estatística (GPEE) da UNESP de Rio Claro. Na obra, os autores sistematizam e sintetizam informações, construção teórica e práticas acumuladas pelo GPEE que se encontram dispersas em outros meios de divulgação: teses, dissertações e artigos publicados pelos autores e outros membros do grupo.

$\mathrm{Na}$ introdução, definem a Educação Estatística como forma de relacionar matemática e o cotidiano. Em forma de revisão bibliográfica, apresentam e contextualizam questões de interesse, objetos de pesquisa e metas da Educação Estatística, citam outros grupos de educação estatística do Brasil. Além disso, organizam os aspectos teóricos mais utilizados GPEE e enfatizam as contribuições de vários autores da Educação Estatística, expõem três conceitos fundantes do trabalho do GPEE: literacia estatística, raciocínio estatístico e pensamento estatístico, e propõem como questão do livro desenvolver essas três competências de forma articulada e contextualizada.

No primeiro capítulo, intitulado $A$ literacia, o pensamento e o raciocinio estatística, são retomados os conceitos fundantes da concepção de Educação Estatística do GPEE. Como uma apropriação do significado de literacia, habilidade de ler, compreender, interpretar, analisar e avaliar textos escritos, definem o conceito de "literacia estatística se referindo ao estudo de argumentos que usam a estatística como referência, ou seja, à habilidade de argumentar usando corretamente a terminologia estatística". (p. 23) Identificam as componentes da literacia estatística, relacionando-as com os objetivos da educação para a cidadania, e afirmam dois tipos de objetivos de aprendizagem

${ }^{1}$ Professor do ICNHS - UFMT/Sinop. E-mail: edsonpb@ufmt.br 
nos estudantes: i) ser capaz de atuar como membro educado da sociedade em uma era de informação e ii) ter uma boa base de entendimento dos temas, ideias e técnicas estatísticas. E, defendem que para desenvolver a literacia estatística dos estudantes é preciso imergi-los em situações de uso da Estatística como evidência nos argumentos encontrados em sua vida como trabalhadores, consumidores e cidadãos.

A segunda competência é o raciocínio estatístico, maneira tal qual uma pessoa raciocina com idéias estatísticas e faz sentido com informações estatísticas. No livro são determinados os níveis de raciocínio. Mas os próprios autores apontam a necessidade de mais pesquisas, tanto para descrever processos cognitivos e as estruturas mentais que os estudantes desenvolvem durante a instrução quanto para se determinar quais atitudes devem ser valorizadas para melhor desenvolver o raciocínio estatístico. Também assumem que o raciocínio estatístico não é ensinado, mas pode ser aprimorado se os alunos aprenderem as regras estatísticas, que podem ser ensinadas por meio da instrução direta.

O pensamento estatístico, a terceira competência, é definido como a capacidade de relacionar dados quantitativos com situações concretas, admitindo a presença da probabilidade e da incerteza, explicitando o que os dados podem dizer sobre o problema em foco. Segundo os autores esta competência também não pode ser ensinada diretamente, mas é possível ser desenvolvida a partir da valorização de hábitos mentais que permitam aos não estatísticos apreciar melhor o papel e a relevância desse tipo de pensamento, provendo experiências que valorizem e reforcem os tipos de estratégias que desejamos que os alunos empreguem no tratamento de novos problemas.

Como no ambiente escolar a Estatística é parte da Matemática, para evitar que o ensino da Estatística seja feito com orientação semelhante à seguida quando se ensina Matemática, é estabelecida a seguinte distinção. Enquanto a Matemática tem sua compreensão ligada a propriedades operacionais e deduções lógicas que caracterizam seu raciocínio, na Estatística, conceitos e procedimentos matemáticos são usados como parte da solução de problemas estatísticos. Apontam como característica fundamental de problemas estatísticos a de que eles comumente não eles têm uma única solução matemática. Na Estatística, os dados são vistos como números inseridos num certo contexto, no qual atuam como base para a interpretação dos resultados, 
que depende de conceituações subjetivas, que extrapolam o conceito matemático e demandam o uso de funções cognitivas diferenciadas, ligadas a associações, interpretações, análises complexas e relações abstratas, dentro de uma compreensão global de um fenômeno (pensamento estatístico) e descrita por meio de uma linguagem própria (literacia estatística).

Os autores esclarecem que não entendem ser produtivo pensar no ensino da Estatística baseado nessas três capacidades consideradas independentemente, pois elas se complementam e somente juntas é que vão abranger a compreensão global da Estatística. Nesse sentido, reforçam que a literacia pode ser vista como o entendimento e a interpretação da informação estatística apresentada, o raciocínio representa a habilidade para trabalhar com as ferramentas e os conceitos aprendidos e o pensamento leva a uma compreensão global da dimensão do problema, permitindo ao aluno questionar espontaneamente a realidade observada por meio da Estatística.

Anunciam a adoção da perspectiva da metodologia de Projetos de Ensino de Estatística, por entenderem que esta inclui habilidades básicas e importantes que podem ser usadas no entendimento de informações estatísticas. Visto que nesta metodologia o foco é a aprendizagem, cujo centro é o aluno. Isto possibilita aos estudantes a oportunidade de produzir os próprios dados e encontrar os resultados básicos, o que os ajuda a tomar as rédeas de seu próprio aprendizado; promove a habilidade de assumir a responsabilidade de resolver seus problemas, como eles terão que fazer em seu ambiente de trabalho e no exercício da cidadania. Apontam que, geralmente, os estudantes não sabem a priori por que precisam saber os conceitos estatísticos, por isso, antes de usar fórmulas, é importante os alunos perceberem a utilidade e necessidade de certa estatística.

Ao tratar do Raciocínio Estatístico, descrevem um Ambiente de Aprendizagem do Raciocínio Estatístico (AARE), como um espaço que tem como foco o desenvolvimento de ideias centrais da estatística ao invés de apresentar conjuntos de ferramentas e procedimentos. Assim, num AARE privilegia-se: o uso de dados reais para encorajar os estudantes na confecção e no teste de conjecturas; o uso de atividades de classe para dar suporte ao desenvolvimento do raciocínio estatístico; a integração do uso de ferramentas tecnológicas adequadas que permitam aos estudantes testar suas conjecturas, a exploração e analise dos dados; a promoção de debates que incluam 
argumentos estatísticos sustentáveis e que foquem nas idéias estatísticas significantes. E professor tem o papel de apresentar o problema, guiar a discussão, antecipar concepções distorcidas ou erradas, assim como dificuldades de raciocínio, e certificar-se de que os estudantes estão engajados nas tarefas e que estão superando suas dificuldades.

Com intuito de favorecer o desenvolvimento articulado da literacia, do pensamento e do raciocínio estatísticos, no segundo capítulo, "Interfaces com a modelagem matemática e com a Educação Crítica" é observada uma concordância de interesses e objetivos da Educação Estatística com a Modelagem Matemática e com a Educação Crítica.

A Modelagem Matemática é conceituada como um método de ensino e de aprendizagem que pode ser empregado nos diversos níveis escolares, e indicam perspectiva da Modelagem Matemática como um ambiente de aprendizagem em que os estudantes são convidados para investigar, através da Matemática, situações extraídas do dia a dia ou mesmo de outras ciências.

A relevância desse método de ensino é ressaltada porque, numa direção, articula o trabalho investigativo em sala de aula com tema mais amplos, relacionados a outras ciências, ou temas do dia a dia, possibilitando inclusive a interdisciplinaridade. Noutra direção, a Modelagem Matemática indentifica-se com uma perspectiva pedagógica focada na formação da cidadania e das consciências política e social do estudante. Nesta segunda perspectiva busca-se valorizar as habilidades individuais necessárias para uma efetiva participação em uma sociedade democrática, similarmente ao proposto na Educação Crítica, que enfatiza a avaliação crítica das práticas que envolvem a matemática, levando em consideração o ambiente cultural que os estudantes pertencem. Essa identificação compõe, segundo os autores, o núcleo central de uma literacia matemática voltada para as mudanças sociais, dirigida para a formação de um cidadão crítico, com poder de argumentação e interessado na discussão de questões sociais que são relevantes para a comunidade.

No entendimento dos autores, o trabalho com a Modelagem Matemática na sala de aula de estatística contribui para o desenvolvimento das competências estatísticas. Desenvolve a literacia à medida que trabalhar com dados reais, que relaciona os dados ao contexto em que estão inseridos, exige dos alunos que interpretem seus resultados, permiti que os estudantes trabalhem juntos (em grupo) e que uns critiquem as interpretações de outros, 
promove julgamentos sobre a validade das conclusões, compartilha com a classe as conclusões e as justificativas apresentadas, avalia constantemente o desenvolvimento das três capacidades em cada domínio da estatística e promove, para cada conteúdo, a triangulação: objetivos -atividades-avaliação.

O Pensamento Estatístico ocorre quando os modelos matemáticos são associados á natureza contextual do problema proposto e o estudante identifica e escolhe adequadamente as ferramentas estatísticas necessária para sua descrição e interpretação. Esse aspecto é citado como fundamental para o desenvolvimento da competência crítica, além de figurar entre as competências listadas para o desenvolvimento da Matemacia, que segundo D’Ambrósio (2005) é a capacidade de interpretar e analisar sinais e códigos, de propor e utilizar modelos e simulações na vida cotidiana, de elaborar abstrações sobre representação do real.

O Raciocínio Estatístico é desenvolvido na Modelagem Matemática como ação didática, visto que os problemas de Estatística também começam com um questionamento e terminam com uma opinião, que se espera seja fundamentada em certos conceitos teóricos e resultados práticos.

A interface Educação Estatística - Educação Crítica, centrada nos projetos de modelagem, ocorre devido ao objetivo de caráter social presente na Educação Crítica que, além de procurar dar significado aos conteúdos estatísticos, procura fazê-lo de forma democrática, incentivando o desenvolvimento, nesses alunos, do espírito crítico, responsabilidade ética e conscientização política. E a ideia de fomentar o conhecimento reflexivo encontra ressonância nos aspectos da Educação Estatística que estabelece como condição básica para um trabalho pedagogicamente significativo, a contextualização dos dados. Também lembram que os princípios de aleatoriedade e de incerteza, que levam a Estatística a se afastar do aspecto determinístico da Matemática, estão em acordo com a crítica à ideologia do falso-verdadeiro, necessária para se trabalhar o conhecimento reflexivo.

Para o engajamento do professor nessa perspectiva educacional são propostos três fundamentos: Contextualizar os dados de um problema estatístico, preferencialmente utilizando dados que, de alguma forma, estejam relacionados com o cotidiano dos alunos; Incentivar a interpretação e análise dos resultados obtidos; Socializar o tema, inserindo-o num contexto político/social e promover debates sobre as questões levantadas. 
No terceiro capítulo, "Projetos de modelagem matemática" são apresentados quatro projetos elaborados e desenvolvidos em situação de sala de aula com base nos princípios da Modelagem Matemática. Estes projetos são apresentados como exemplos de atividades que contribuem para fomentar junto aos alunos o desenvolvimento das principais competências estatísticas e, procuraram ir ao encontro dos objetivos de ensino traçados pela Educação Crítica.

No primeiro projeto, "A estatística, o mercado de capitais e a responsabilidade social", foi desenvolvido por Campos (2007) num curso de Ciências Econômicas, constitui basicamente de um processo de discussão e investigação sobre mercado de capitais, formulação e experimentação de estratégias de investimentos em um mercado virtual durante determinado período de tempo. A descrição do projeto é realizada em cinco etapas e avalia o trabalho realizado em cada uma das etapas, observando os princípios da Educação Estatística, os conteúdos abordados e os debates realizados.

No segundo projeto, "Usando simulação para abordagem de conceitos de distribuição amostral, margem e erro e níveis de confiança", é realizada a modelagem a partir de simulação de resultados amostrais, a partir de informações populacionais conhecidas. Assim, os resultados finais das eleições presidenciais de 2010 são constituídos um ambiente de aprendizagem para abordagem de conceitos estatísticos.

O terceiro projeto, "O teste do qui-quadrado", que, assim como o primeiro, faz parte da tese de Campos (2007), é ambientado na disciplina de Estatística II no curso de Ciências Econômicas, e teve motivação a partir da crítica a um exemplo/exercício apresentado por um livro texto. Então os alunos foram orientados a realizar pesquisas de opinião, após escolhas de temas levantados por eles mesmos, a recolherem uma amostragem, fazerem o inquérito e apresentarem relatórios com o objetivo de verificarem a associação entre variáveis. A avaliação do projeto foi considerada positiva porque trouxe a tona vários temas polêmicos que acabaram por motivar os alunos. Também porque os aspectos ligados aos problemas relativos a amostragem foram bastante esclarecedores, e os alunos puderam vivenciar as conseqüências de amostragens não criteriosas em pesquisas de opinião.

O quarto projeto, “O problema da fila”, Também realizado em um curso de Ciências Econômicas de uma instituição particular, período noturno, 
com alunos trabalhadores, boa parte funcionários em bancos. Os alunos apresentaram um problema relativo ao tempo de espera de um cliente na fila do caixa do banco. A avaliação estatística indicou que os dados eram bastante confiáveis e mostrou as limitações do modelo geral com relação a regressão que não considerava o intercepto nulo. Além disso, possibilitar aos alunos uma intervenção no contexto, pois o modelo elaborado foi utilizado no ambiente de trabalho de alguns alunos.

Os relatos dos projetos também se constituem em bons exemplos do uso do computador como instrumento em projetos contextualizados. Mostra como a aprendizagem centrada nos alunos possibilitou a tomada de decisão, também são aproveitados pelos autores para retomar, como o trabalho pedagógico cunhado na conjunção e interfaces da tríade Educação Estatística - Modelagem Matemática - Educação Crítica, além de desenvolver as competências estatísticas que compõe o núcleo central da Educação Estatística: literacia, pensamento e raciocínio estatísticos, contribui para superar o que Skovsmose (2000) chama de paradigma do exercício, no qual "o professor apresenta as idéias e técnicas matemáticas e depois os alunos trabalham os exercícios" (p.67).

A leitura do livro por si só já permite a iniciantes em Educação Estatística e Educação Matemática o contato com os conceitos da área de pesquisa de forma clara, concisa e articulada com a demanda por um ensino contextualizado e significativo. Também ressalto que as citações e referências bibliográficas apresentadas se constituem sugestões para interessados em conhecer mais sobre Educação Estatística e sobre o trabalho do GPEE, bem como para ampliar compreensões sobre Modelagem Matemática e Educação Crítica. Informamos que toda a construção teórica e dois dos projetos apresentados encontram-se em Campos (2007).

O livro chama a atenção, pela clareza conceitual e correção com que são articuladas teoricamente as competências estatísticas, com a Modelagem Matemática como metodologia e ambiente de aprendizagem com a Educação Crítica, através de projetos de ensino. Compreendo que essa articulação nos indica uma perspectiva de abordagem teórica que contempla inclusive as demandas e proposições expostas nas diretrizes curriculares nacionais da educação básica.

No esforço de compreender o ensino por competências, a leitura 
deste livro nos permite compreender, conforme afirma Machado (2005), que as idéias de disciplina e competência não disputam o mesmo espaço curricular, no ensino por projetos. Pois, tanto na construção teórica como nos relatos dos projetos podemos perceber como a disciplina (Estatística) explicita um quadro de conceitos, conteúdos e procedimentos, enquanto as competências (literacia, raciocínio e pensamento) são situadas no caminho da articulação entre o conhecimento e a organização significativa dos dados e conceitos, assim como constituem uma tentativa de compreensão do modo como o conhecimento explícito enraiza-se no conhecimento tácito. Além disso, os relatos dos projetos nos servem de exemplo de como o ensino por projeto, centrado no aluno, promove uma ampliação nos objetos e nos objetivos dos estudos, e de como o conhecimento justifica-se e torna significativo à medida que é mobilizado a serviço dos alunos.

Finalmente ressalto que a leitura deste livro serve de inspiração para elaboração de projetos com a intenção de exercitar uma prática pedagógica que transcenda a limitações da prática disciplinar, tanto na formação inicial de professores como na educação básica.

\section{Referências bibliográficas}

CAMPOS, Celso Ribeiro. Educação Estatística: uma investigação acerca dos aspectos relevantes à didática da Estatística em cursos de graduação. 2007. 242 f. Tese (Doutorado em Educação Matemática) Universidade estadual Paulista, Rio Claro, 2007.

D’AMBRÓSIO, Ubiratan. Etnomatemática - elo entre as tradições e a modernidade. $2^{\mathrm{a}}$ ed. Belo Horizonte: Autêntica, 2005.

LINS, R. C. Por que discutir teoria do conhecimento é relevante para a Educação Matemática. In: BICUDO, M. A. V. (Org.). Pesquisa em Educação Matemática: concepções e perspectivas. São Paulo: Editora Unesp, 1999 p. 75-94.

MACHADO, Nilson José. Interdisciplinaridade e contextuação. In: Instituto Nacional de Estudos e Pesquisas Educacionais Anísio Teixeira. Exame Nacional do Ensino Médio (ENEM): fundamentação teórico-metodológica. - Brasília: INEP, 2005, 41-54.

SKOVSMOSE, Ole. Cenários para Investigação. Bolema - Boletim de Educação matemática, Rio claro, ano 13, n. 14, p. 66-91, 2000.

Submetido em 25/02/2012

Aprovado em 11/02/2014 